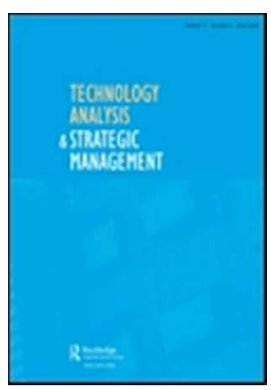

Human capital of entrepreneurial teams in nascent hightech sectors: a comparison between Cleantech and Internet

\begin{tabular}{|r|l|}
\hline Journal: & Technology Analysis \& Strategic Management \\
\hline Manuscript ID & CTAS-2016-0036.R2 \\
\hline Manuscript Type: & Original Article \\
\hline Keywords: & Hi-Tech industries < RESEARCH SITE, Entrepreneurship < DISCIPLINES \\
\hline DISCIPLINE: & Entrepreneurship \\
\hline METHODOLOGY: & Quantitative \\
\hline \multicolumn{2}{|l}{} \\
\hline
\end{tabular}

SCHOLARONE ${ }^{m}$

Manuscripts 


\title{
Human capital of entrepreneurial teams in nascent high-tech sectors: a comparison between Cleantech and Internet
}

\author{
Paola Garrone ${ }^{a}$ (paola.garrone@polimi.it) \\ Luca Grilli ${ }^{\text {a }}$ (1uca.grilli@polimi.it) \\ Boris Mrkajic ${ }^{a}$ (boris.mrkajic@polimi.it) \\ ${ }^{a}$ Politecnico di Milano, Department of Management, Economics and Industrial Engineering \\ Via R. Lambruschini, 4b - 20156, Milan, Italy \\ ${ }^{*}$ Corresponding author
}




\section{Abstract}

We use an inductive approach to understand what types of founders' human capital, at individual and team levels, are necessary to recognize and exploit entrepreneurial opportunities. A sample of 195 founders who teamed up in the nascent phases of Cleantech and Interned-based sectors is analysed. The results suggest a twofold moderating effect of the sectoral context. First, a more hard science-based and complex sector like Cleantech demands technically more skilled entrepreneurs, but at the same time, it still requires fairly commercially experienced and economically competent individuals. Furthermore, the business context also appears to exert an important influence on team formation dynamics: individuals are more prone to team up with cofounders possessing complementary know-how when they are starting a new business venture in the Cleantech rather than in the Internet-based sector. Overall, these results stress the role of the specific high-tech business context at stake when analysing entrepreneurial team composition patterns.

\section{Keywords}

Entrepreneurial team composition; founders' human capital; business context; homophily; functionality. 


\section{Introduction}

Technological change and innovation are possible only if technological opportunities are recognized and exploited by economic organizations (Schumpeter 1912, 1942). Especially new firms in the nascent phase of an industry are deemed to play a key role in this respect (Schumpeter 1912). For a successful entry of new firms, knowledge of the specific features of the technology and the targeted markets are often considered as essential pre-conditions (Shane 2000). Of course, all this knowledge is often not embodied in a single individual. Thus, entrepreneurial teams have to be formed. If the early literature initially claimed that the formation of entrepreneurial teams might be "random" and in most cases difficult to assess, opinion that the composition of entrepreneurial teams is rational and analyses of the roots of team formation patterns, have gained momentum (Cooney 2005, Ruef, Aldrich and Carter 2003). In this respect the literature on economics of entrepreneurship (e.g. Ganotakis 2012) has recently been cross-bread with the upper echelon strategic management and organisational behaviour perspectives and both highlight that the founding team composition impacts start-up's performance (for an overview see Klotz et al. 2014).

In that vein, we adopt a competence-based lens of investigation and argue that foundation of a firm in high-technology industries is likely to require more skills than those one individual usually possesses, indirectly forcing the individuals to combine their abilities in teams, in order to start a new venture successfully (Vyakarnam, Jacobs and Handelberg 1999). In this area, knowledge about how founding teams are formed in high-tech sectors is still not conclusive. Moreover, despite vast works on the composition of entrepreneurial and top management teams (see e.g. Aldrich and Kim 2007, Forbes et al. 2006), the fact that teaming up patterns of entrepreneurs may be highly industry-specific has been to some extent neglected (Welter 2011), 
despite the diffused agreement that the organisation of similar activities, such as innovation, do considerably differ across technologies and sectors (Malerba 2002). One important exception in the domain of technology analysis is represented by the study of Breschi et al. (2014). They conduct an analysis on a sample of 72 new patenting firms and highlight how pre-entry knowledge on demand's characteristics is more associated to entrepreneurial teams in electronics rather than those active in biotechnology. Overall, their analysis puts forward the idea that human capital requirements have a distinct nature depending on the high-tech sector on which the new firm is called to operate in.

The present work aims at corroborating and also deepening and extending Breschi et al. (2014)'s interesting results. A number of differences characterize our work with theirs. First, our fundamental unit of analysis is not the team as in their case, but it is represented by the single entrepreneur. In particular, we study how the human capital of these individuals combine together and form entrepreneurial teams, and to what extent the business context is a missing and an important driver of entrepreneurial team composition. Secondly, our focus is on two important high-tech sectors, Cleantech and Internet, which are observed at their respective nascent phase. While Breschi et al. (2014) analyse three different technological sectors (Biotechnology, Electronics and Medical devices), they do not control for the different maturity stages of the underlying technologies and markets, which may in fact require different human capital competencies from entrepreneurial teams. This circumstance could represent a potential confounding factor in the analysis of the relationship between human capital of a founding team and the technological and market specificities of an industry. However, it could also be argued that a co-evolution dynamics may exist between industrial eco-systems and entrepreneurs' human capital, i.e. that the development of a new high-tech sector is shaped by the human capital 
of the pioneering founders that initiate specific technology trajectories and determine business conducts which, in turn, imprint the typology and characteristics of the subsequent waves of entrepreneurs (Packalen 2015). Indeed, this perspective would make less compelling the need to control for the life cycle of an industry, but at the same time it also makes the nascent phases the purest to analyze and of key relevance to understand the whole sectoral dynamics. Third, our analysis complements theirs insofar as it includes also high-tech ventures that do not necessarily use that formal mechanism (patenting) for protecting innovation. In a nutshell, by extending and deepening the analysis of Breschi et al. (2014), we confront different theoretical views about founders' human capital and team formation patterns in two seemingly similar high-tech sectors in their nascent stages. By doing that, we are capable to offer new insights on these dynamics, which could be useful to a series of stakeholders, including yet not limited to policymakers. The eventual detection of structural differences may in fact invoke the design of vertical industrial policy measures tailored to each specific sector and capable to foster entrepreneurial activities in that specific domain.

In the present study, we compare 195 founders who created their ventures in the nascent phases of the Cleantech and Internet-based sectors to learn about the differences these two sectors entail on the following dimensions: (i) the source and type of individuals' knowledge, (ii) the knowledge dissimilarity between founders and (iii) the knowledge complementarity within founders of the same venture. Basically, we posit and then test that sectoral differences have an impact not only on the human capital's endowments of entrepreneurs, but also on the way different founders' human capital characteristics are combined in an entrepreneurial team. 
The rest of the paper is organized as follows. Section 2 introduces the theoretical background. Section 3 describes the sample and the variables used in the empirical analysis. Section 4 illustrates the methodological approach and reports the results. Section 5 concludes the paper.

\section{Theoretical background}

The ability to identify situations in which resources can be combined to form a new firm depends strongly on the human capital of the individuals (e.g. Eckhardt and Shane 2003, Gimeno et al. 1997). In particular, founders' knowledge and skills are shown to be critical elements of business opportunity recognition (Shane and Venkataraman 2000), and a successful creation of a firm (Becker 1975). Founder's human capital is even more relevant in the high-tech context, since the characteristics of a technology-based firm are intimately related to the characteristics of their founders (Cooper and Bruno 1977, Feeser and Willard 1990).

Nevertheless, firm creation dynamics is not only influenced by entrepreneurs' human capital at the individual level. Solo entrepreneurs are unusual in general, and they are even more seldom in high-tech start-ups (Shane 2003). A new firm could acquire the necessary knowledge by hiring individuals as employees, but this knowledge may come too late and at high cost. Entrepreneurial judgement is highly idiosyncratic, and it is far more effective if the knowledge is already possessed by members of the founding team (see the "cephalisation" argument of Knight 1921). Therefore, the integration of knowledge is necessary as well, which may be distributed among different individuals, i.e. firm cofounders. The way that knowledge is combined within teams is of paramount importance, as empirical evidence demonstrate that different combinations of human capital of cofounders implies different firm outcomes (e.g. Colombo and Grilli 2005, 2010). 
As to studies in entrepreneurship, most of the literature to date have focused on the quantitative nature of human capital (Dimov and Shepherd 2005). However, considering only quantitative aspects may be incomplete and the qualitative side of human capital should not be neglected in order to fully understand knowledge as a vital resource of the new-borne firm. ${ }^{1}$ In some cases, differences in quantity may matter even less than differences in quality. Combination of both aspects of human capital provides the most comprehensive picture (Grilli 2011). This is done by distinguishing between different types of education and different types of experiences (similarly to Colombo and Grilli 2005, 2010). Education is classified by distinguishing the technical and scientific field on the one side, from the economic and managerial domain on the other side. Professional experience is broken down even more profoundly, in two dimensions. The first dimension is similar to education typology, namely technical and production experience, against commercial experience. The second dimension makes a difference between specific and generic knowledge (Becker 1975, Colombo and Grilli 2005). Specific knowledge consists of capabilities that founders can directly and immediately apply in the newly created firm, as it had been acquired through prior work experience in the same industry in which the new firm operates, that is, through industry-specific work experience. Generic knowledge relates to the general knowledge acquired by entrepreneurs through professional experience in industries different from the one in which the new firm operates.

Relating to this point, from the sociological literature on group formation, two of the most important, albeit contradictory, mechanisms that influence team composition are established -

\footnotetext{
${ }^{1}$ We do not consider here another interesting aspect which is the motivational forces behind the choice of creating the entrepreneurial venture, and how these interact with entrepreneurial team formation and the human capital of founders. We have only partial information about these aspects, where it has been difficult to ex-post collect reliable ex-ante information about the motivations of entrepreneurs at time of founding, due to likely cognitive and retrospective biases at work. However, we did not find any strong correlation between specific motivations and the investigated human capital dimensions that are the object of our study. If therefore we don't expect this omission to seriously interfere with the dynamics highlighted in our study.
} 
homophily and functionality, as rooted in the competence-based context. Homophily refers to the selection of other team members on the basis of similar characteristics (McPherson, Smith-Lovin and Cook 2001). In particular, we focus on achieved characteristics (e.g. education, occupation), as they seem to be driving team formation by dominantly impacting social networks and connections that prospective founders rely on when seeking for cofounders. Additionally, the similarity of individuals in the achieved characteristics is believed to enable a higher level of interpersonal understanding and trust, which might impact success of the founded venture in the later phases.

On the other hand, functional theories study the extent to which team members possess diverse and complementary competencies that influence the formation of the team (Gartner 1985, Vesper 1990), and play a role in the subsequent success of the firm (Ruef, Aldrich and Carter 2003). They draw parallel with the resource dependence theory, which vouches that firms in need of specific complementary resources form ties with other firms which can complement what they are missing (Katila, Rosenberger and Eisenhardt 2008). The same may hold for prospective founders, which form heterogeneous teams to increase range of competences, and by that, chances of success (Eisenhardt and Schoonhoven 1990). Accordingly, high-tech sectors, given the wide and deep knowledge-base they require from firms, are particularly highlighted to call for a resource-seeking approach, rather than an interpersonal attraction approach when founding teams are formed (Forbes et al. 2006).

Finally, even though team composition has been intensively studied to date, the majority of research was focused on the organisational business framework, i.e. the 'traditional' within firm perspective. Analysis of the motives, timing and dynamics of entrepreneurial activity has been investigated without significant consideration of the context and related influence (Welter 2011). 
Richness of contexts and diversity of environments in which new ventures have been created and are called to operate in, and how entrepreneurial activity is contingent upon them, has been overlooked, both theoretically and empirically (Zahra 2007). More specifically, there is a lack of elaborate exploration on how the industrial environment shapes individuals' decision to team-up and constitute a new venture (Vyakarnam, Jacobs and Handelberg 1999).

There are numerous sectoral characteristics that could potentially have an impact on that dynamics. Different types of operating market (in terms of market concentration, nature of competitors, different degrees of market fragmentation, etc.) might impose different challenges or opportunities to entrepreneurs (Ruiz-Ortega and Garcia-Villaverde 2010). In this respect, Cleantech and Internet share similarities and differences that make their comparison plausible and interesting at the same time. Cleantech, similarly to Internet, encompasses a wide spectrum of business applications (Hammar and Löfgren 2010) as well as embrace a wideness of potential customers (Kemp and Volpi 2008); but at the same time, it is basically devoted to a single (albeit rather important) goal such as pollution abatement, while Internet has a more multi-purpose use. Moreover, more specifically to the theme of our analysis, Cleantech is considered a far more hard science-based and technologically intensive industry than Internet (Sawhney and Kahn 2012). This greater technological complexity should call for a relatively stronger technological expertise.

To what extent entrepreneurial team formation in the high-tech arena is influenced by the underlying technology and market-related characteristics is explored in the following empirical analysis. 


\section{Sample and Variables}

We draw on the RITA (Research on Entrepreneurship in Advanced Technologies) dataset, which is the most comprehensive information source presently available on Italian high-tech entrepreneurial business ventures (e.g. Colombo and Grilli 2010, 2013). RITA dataset is constructed through a series of four national surveys (in 2000, 2002, 2004 and 2008) of the population of owner-managed new technology-based firms active in the country. The surveys were based on a questionnaire that was sent to the contact person of target firms (i.e. one of firm's owner-managers), while the data reliability was enhanced by conducting phone or face-toface follow-up interviews. One of the questionnaire's sections demanded detailed information on the human capital characteristics of firms' founders, comprising founder's formal education and prior work experience. Data on both dimensions of human capital are present in quantitative aspects (e.g. duration), but also in qualitative aspects (e.g. the field of education or the function exerted in the prior work experience). This information is predominantly utilized in the paper. Other sections include further questions concerning the characteristics of firms and the technological and business environment in which firms operate.

We restricted the sample on firms for which we were able to create a complete dataset. We also included only firms that belong to the two sectors of interest, i.e. the Cleantech and the Internet-based sectors, comprising firms active in components and equipment for renewable energy, production of renewable energy, environmental services on the one side, and Internet services, e-commerce and multimedia web-based services on the other side.

In order to convey a fair comparison, we identified the time-windows that correspond to the nascent phases of the two sectors - we included the Internet-based firms created from year 1990 to year 2000 and Cleantech firms between years 1997 and 2007 - and for which we could obtain 
complete information. Two $\chi^{2}$ tests $\left(\chi_{c}{ }^{2}(3)=5.981\right.$ and $\left.\chi_{I}{ }^{2}(3)=4.305\right)$ show that there are no statistically significant differences between the distribution of the final sample of firms across geographic areas (at macro regional level) and the corresponding geographical distribution of Cleantech and Internet-based RITA firms from which the sample was drawn. Furthermore, in order to ensure representativeness of our subsample, we compared it with the micro-data of a pan-European dataset (VICO) along some basic statistics, ${ }^{2}$ and have found no considerable dissimilarities. The choice on the respective initial stages was mainly made using statistics on venture capital (VC) investments dynamics. Despite differences in the order of magnitude, the investment growth rates of the two sectors were fairly similar: around a 10-time increase in investing intensity from the beginning to the end of their nascent periods. Internet-based sector was incepted in the beginning of 1990's and ended by the dot-com bubble burst (2000), while Cleantech nascent stage has arguably started around (or some years before) year 2000 and ended by 2007 , when the record-breaking increase in investment activity was documented. During the following years the incline in investments has slackened, even with few quarters in which a decline has been recorded. ${ }^{3}$ Beside statistics on VC activity, the identification of the early stages of the two investigated sectors was also corroborated through several different academic sources (see for example Fransman 2004 for what concerns the Internet-based sector, and Petkova et al. 2014 for Cleantech) and popular press.

We also handled the outliers in terms of firm size (number of employees who are not founders) by cutting above $95^{\text {th }}$ percentile in our baseline analysis, in order to keep the two subsamples comparable. We have checked sensitivity of the results with respect to the cut-off point $\left(90^{\text {th }}, 99^{\text {th }}\right.$ and $100^{\text {th }}$ percentile) and we have found no major differences. Finally, solo

\footnotetext{
${ }^{2}$ For more details regarding VICO dataset, see Bertoni and Marti (2011).
}

${ }^{3}$ Further details can be found in NuWire Investor (2008). 
founders were dropped from the sample, since in these solo-organized ventures the team dimension does not exist by definition. At the end, we were left with 195 founders of 90 Italian technology-based firms, with 54 active in the Cleantech sector and 141 active in the Internetbased sector. Most of the entrepreneurial teams in the sample are formed by two or three founders (i.e. $74.8 \%$ of the entrepreneurs are in a team of two or three members); while larger founding teams are relatively rare which is coherent with the typical founding size of a new technology-based firm (e.g. Colombo and Grilli 2005). No structural differences hereof were observed between the two sectors.

Three sets of variables are used in the analysis and they are summarized in Table 1. The first set comprises founders' human capital variables related to formal education and prior work experience, at the individual level. The former is represented by continuous variables, standing for years of formal education of a founder. Distinction is made between higher education in scientific/technical versus economical/managerial disciplines. A similar aggregation is made for prior work experience. Nonetheless, two different typologies are introduced. The first distinction is made with respect to function served during the prior experience (i.e. technical or production functions versus commercial functions). The second distinction is made with respect to sector in which that experience was obtained (i.e. the same sector of the new-borne start-up versus a different sector).

[Table 1]

The other two sets of variables are related to team composition, i.e. dissimilarities and complementarities in human capital of cofounders of the same firm. Dissimilarity indicators are derived from the six variables related to founders' human capital, and represent the number of 
years for which education or experience of founder differs from education or experience of the average cofounder within the same firm. ${ }^{4}$ We take Euclidean distance as a measure of dissimilarity and in this case, we selected 1-norm distance (due to the 1-dimensional difference). Mathematical definition is given in Equation (1):

$$
\text { Dissimilarity }_{j}=\mid \text { founder }_{j}-\operatorname{avg}\left(\text { cofounders }_{j}\right) \mid,
$$

where $j$ can be education, specific or generic work experience. Dissimilarity is an absolute value of difference between a founder's total years of education or work experience, and the average years of the corresponding variable for the cofounders.

The third set of variables includes information related to complementarity between cofounders' human capital and leans on differences in disciplines or functions background. In other words, complementarity is expressed in terms of type of education and prior work experience, i.e. it also relies on qualitative information related to human capital. For instance, a founder is, with respect to formal education, considered more complementary to her/his cofounders if $\mathrm{s} / \mathrm{he}$ has longer technical or scientific education, while the cofounders possess a longer economic or managerial education. Complementarity represents number of years for which founder differs from the average cofounder in the same firm, across the qualitative dimensions. Again, the measure of complementarity (distance) is chosen to be Euclidean. In particular, 2-norm distance is used as it is shown in Equation (2), due to the 2-dimensional nature of the construct:

\footnotetext{
${ }^{4}$ To keep the complexity of the analysis to a manageable degree we do not distinguish in this case, and in the subsequent one on complementary measures, the different typologies of disciplines and functions across education and experience.
} 


$$
\text { Complementarity }_{j}=\sqrt{\left(\text { founder }_{k j}-\operatorname{avg}\left(\operatorname{cofounders~}_{k j}\right)\right)^{2}+\left(\text { founder }_{m j}-\operatorname{avg}\left(\operatorname{cofounders~}_{m j}\right)\right)^{2}},
$$

where $j$ can be education, specific or generic work experience, $k$ can be technical (in case of education) or technical and production function (work experience), $m$ can be business (education) or commercial function (work experience). A zero value for the indicator means that there is no complementarity at all. For instance, a founder has identical education as her cofounders. On the other hand, greater values imply greater complementarity, e.g. a founder has diverse education from her cofounders.

\section{Empirical analysis}

In order to shed light on the investigated issue, we deploy a two-step statistical analysis. We first use multiple multivariate methods to gain a more complete understanding of the phenomenon under investigation, and follow them up with univariate analysis to break down the differences on a single variable base. Correlation matrix of the variables is presented in Table 2, where no serious correlation is noticed, except for variables, which are by construction correlated, e.g. dissimilarity and complementarity of education.

[Table 2]

\subsection{Multivariate analysis}

Different types of multivariate analysis are used to obtain stronger relevance of the results. First, a cluster analysis is executed. In general, it is an iterative technique which classifies a sample of entities (individuals or objects) into a smaller number of mutually exclusive subgroups (clusters) based on the similarities among the entities (Ketchen and Shook 1996). We 
operationalize it following a number of standard steps suggested by Ilango, Subramanian and Vasudevan (2011) and adapting the interpretation of the results to our specific context. ${ }^{5}$ Namely, by the availability of our data, we do exactly know the classification with respect to the sector of activity into two groups, Cleantech and Internet-based. The idea is to intentionally neglect exante this information, execute the clustering with all the variables that we want to use in the comparison of the two groups, and subsequently compare the resulting groups to the original information. Empirically, if there are strong differences between the two groups on the level of the used variables, each of the two resulting clusters should contain Cleantech and Internet-based entrepreneurs in different proportions. Accordingly, our expectation is that if the industrial context does play a role in affecting the investigated dynamics, we should obtain two clusters, one that contains majority of Cleantech entrepreneurs and another one that contains majority of Internet-based entrepreneurs.

We execute clustering procedure initially only for variables related to founders' human capital at the individual level (number of founders, education and work experience variables). Results in Figure 1(a) shows that $53 \%$ of the first cluster is made by Cleantech firms, while the second one contains only $18 \%$ of Cleantech firms. Respectively, Internet-based firms account for $47 \%$ in the first cluster and $82 \%$ in the second one. This difference is offering us an insight into the fact that there are differences between the Cleantech and the Internet-based sectors when it comes to human capital of individual founders. An identical procedure was followed using only variables

\footnotetext{
${ }^{5}$ The chosen clustering procedure is the partitioning method, i.e. the k-means method, which is superior to the other methods (e.g. hierarchical) as it is less affected by the presence of outliers and irrelevant clustering variables, and less computationally demanding (Mooi and Sarstedt 2011). The usual problem associated with the application of kmeans, which relates to the fact that the number of clusters needs to be pre-specified, is overcome by definition in our context. The clustering variables are normalized in order to have a fair participation of all the variables, regardless of their scale. Finally, the recommended sample size is at least $2^{n}$, where $n$ equals the number of clustering variables is given in (Mooi and Sarstedt 2011). Having 195 observations in our analysis makes us hence comfortable to use up to seven clustering variables.
} 
related to cofounding teams (i.e. dissimilarity and complementarity variables) and even more neat results are obtained. Namely, looking at Figure 1(b), one may notice that there are peculiarities related to the Cleantech when compared to the Internet-based sector in terms of entrepreneurial team foundation patterns, as the first cluster is comprised of $68 \%$ of Cleantech entrepreneurs, while the second one has only $23 \%$. Lastly, as robustness check, clustering was performed on all the variables at the same time and the previous results were confirmed (see Figure 1(c)), even though the larger number of variables is associated to a weaker separation. The detailed results of the cluster analysis are summed in Table 3.

We also use MANOVA (Multivariate analysis of variance) and Hotelling's T-squared test to demonstrate the robustness of the results obtained with the cluster analysis. In our case, the purpose of the techniques is to test whether the vectors of means for the two groups are sampled from the same sampling distribution (Carey 1998). Both tests yield the same results as the cluster analysis, i.e. they show that the sector of activity is implying differences for founders' human capital and founding team dissimilarity and complementarity.

[Figure 1]

[Table 3]

\subsection{Univariate analysis}

Multivariate analyses confirmed that there are differences in founders' human capital and founding team-up patterns between the Cleantech and the Internet-based sectors. In order to dig into these differences and infer which dimension of the entrepreneurs' human capital is more responsible for this global result, we use standard univariate analysis, i.e. t-tests. 
Results are presented in Table 4 and Table 5, respectively. We report the means for the two groups of observations together, with standard deviations and most importantly, the corresponding t-test p-values (Null hypothesis $H_{0}: \mu_{\text {Cleantech }}=\mu_{\text {Internet }}$ ). Statistically significant differences are found for a number of variables.

[Table 4]

The number of founders appears not be disparate, i.e. average number of founders for both sectors is approximately 3. As far as founders' human capital variables are concerned, differences in means are substantial for both technical education and work experience in technical functions, regardless of the specific or generic nature of experience. Specifically, Cleantech requires on average more technical knowledge and experience out of an entrepreneur. It is interesting to single out that the difference between the two sectors is even larger for specific work experience. Entrepreneurs active in the Cleantech sector possess higher level of the samesector experience. On the contrary, the results show no differences in terms of business education or commercial experience. Namely, as it may be seen in Table 4, there are no statistically significant differences between means of the two groups for business degree education and commercial experience independent of its type (specific or generic).

Variables describing the cofounding team as a whole are telling a different part of the story related to founding team composition, i.e. they are explaining the way founders' human capital is combined. Firstly, the t-test results (Table 5) show that neither the level nor the field of education makes a difference for the two groups of entrepreneurs. However, this does not mean that there is no dissimilarity or complementarity, but only that the entrepreneurial teams in both the 
Cleantech and the Internet-based sectors are diverse and complementary to the same degree in their educational background, and sectoral differences are not playing an important role in this respect.

[Table 5]

The finding also offers evidence that the type of prior work experience indeed does matter for founding team composition. Differences in the complementarity of founders' specific experience are particularly high. Moreover, we find that different sectors demand different combination of specific work experience within an entrepreneurial team, with the Cleantech businesses presenting more dissimilar and complementary endowments in terms of founders' specific work experience than Internet-based ones. This adds to the findings on the individual level regarding previous work experience in the same sector of activity - it represents the main difference between the analysed sectors, and holds for both individuals' human capital and entrepreneurial team composition. Finally, we can observe in Table 5 that the complementarity of work experience in other sectors of activity is an important aspect for entrepreneurial team composition of high-tech industries (i.e. there relatively high mean values of the index ComplementarityInGenericExperience for both sectors), but difference in sectoral characteristics does not influence that notably (i.e. there is no a statistically significant difference in the mean value of the index between the two sectors). ${ }^{6}$

\footnotetext{
${ }^{6}$ Furthermore we also explore dimensions such as serial entrepreneurial activity and prior managerial experience on which we have information only a sub-sample of entrepreneurs. This additional analysis yields no differences between the two sectors along the additional dimensions.
} 


\section{Conclusion}

Our findings support and extend existing human capital research related to entrepreneurial team composition in high-tech sectors (see in particular Breschi et al. 2014). Although some dimensions of founders' human capital and team composition patterns were found not to be significantly influenced by the sector of operations (e.g. business and commercial competences), for a number of human capital dimensions the differences were indeed significant. In fact, as for individual founders and their human capital, the importance of technical, scientific and production knowledge appear to be expectedly high for both sectors, yet much more prominent in the Cleantech. The difference emerged to be even larger for specific work experience. Arguably, the scientific depth and complexity of the nascent Cleantech sector could have required more intense technological knowledge relatively to the nascent Internet-based sector.

Our results also show that Cleantech founding teams require more diverse and complementary combination of specific work experience than Internet-based teams. This specific finding supports the functionality view on entrepreneurial team formation (Gartner 1985, Vesper 1990). Prospective entrepreneurs are more prone or even compelled to go beyond their existing social network and homophily patterns (Aldrich and Zimmer 1986, McPherson, Smith-Lovin and Cook 2001) built through education and prior work experience when they intend to engage in entrepreneurial activity in the Cleantech sector. In other words, even though functionality is unmistakably present in entrepreneurial team composition as functional theorists claim (Eisenhardt and Schoonhoven 1990, Gartner 1985, Vesper 1990), the extent to which it matters seems to be moderated by the level of technological and scientific complexity and the width of the competencies required by the sector of operation. 
These results have valuable implications for prospective high-tech entrepreneurs, technology executives and interested policymakers. High-tech firms' founders and managers can gain insights into what kind of combination of human capital is the most common in diverse industrial contexts. Cleantech founding teams are comprised of more complementary skill set, and that should be considered when starting a new venture in that sector in order to increase probability to recognize a promising opportunity and to pursue it subsequently. An effective entrepreneurship policy should be designed accordingly too. Governmental intervention aiming at sustaining entrepreneurial dynamics should account for the fact that sector of activity reshapes team composition patterns. In other words, particular caution should be exerted when utilizing a fairly common practice of transferring programs across sectors; any dynamics envisaged for founders' human capital should be checked against the new business environment. For instance, more technologically-intensive sectors might require from entrepreneurs to search for cofounders beyond their social networks and team-up with the so-called 'strangers' (Ruef, Aldrich and Carter 2003) in order to find cofounders with diverse and complementary prior experience in the same sector. This effort could be cumbersome and in turn could entail more resources, thus requiring more governmental support than other cases. These results are also relevant for the design of environmental policies. Cleantech entrepreneurship promotion is increasingly acknowledged as the key to sustainable development goals, as starts-ups are more probable than incumbents to take business opportunities that foster sustainable development (Hall, Daneke and Lenox 2010).

Our results also confirm that Cleantech is a challenging sector that requires more attention from the government, as not only the quest for a complementary match might be demanding, but communication and management during the process of firm foundation and growth can be even 
more challenging. In this respect, "soft" policy interventions and brokerage activity aimed at easing on-line and off-line meetings between prospective Cleantech entrepreneurs could be of great value. The brokerage activity may also have an indirect impact on investment dynamics. By helping individuals and prospective entrepreneurs to better connect each other, brokerage activities may in fact increase the probability that more complete entrepreneurial teams are formed. In turn, this makes the newly created start-ups more attractive towards VC that are often found to keep into great consideration in their investment selection criteria the quality of a team rather than simply be driven by a compelling technology (e.g. Zacharakis and Meyer 2000). In sequence, as shown by the extant literature, $\mathrm{VC}$ investments lead to improved performance and increased success prospects for the backed venture (e.g. Baum and Silverman 2004).

\section{Acknowledgements}

The authors wish to thank two anonymous referees for their useful comments.

\section{References}

Aldrich, H.E. and PH Kim 2007. Small worlds, infinite possibilities? How social networks affect entrepreneurial team formation and search. Strategic Entrepreneurship Journal 1: 147-165.

Aldrich, H.E. and C. Zimmer 1986. Entrepreneurship Through Social Networks. University of Illinois at UrbanaChampaign's Academy for Entrepreneurial Leadership Historical Research Reference in Entrepreneurship.

Baum, J. and B.S. Silverman 2004. Picking winners or building them? Alliance, intellectual, and human capital as selection criteria in venture financing and performance of biotechnology startups. Journal of Business Venturing 19: 411-436.

Becker, G.S. 1975. Human Capital: A Theoretical and Empirical Analysis with Special Reference to Education. 2nd ed. New York City, NY: NBER.

Bertoni, F. and J. Marti 2011. Financing Entrepreneurial Ventures in Europe: The VICO Dataset. SSRN Scholarly Paper No. ID 1904297. Rochester, NY.

Breschi, S., C. Lenzi, F. Malerba and M.L. Mancusi 2014. Knowledge-intensive entrepreneurship: sectoral patterns in a sample of European high-tech firms. Technology Analysis \& Strategic Management 26: 751-764.

Carey, G. 1998. Multivariate Analysis of Variance (MANOVA). Teaching Notes, University of Colorado, Boulder.

Colombo, M.G. and L. Grilli 2005. Founders' human capital and the growth of new technology-based firms: A competence-based view. Research Policy 34: 795-816.

Colombo, M.G. and L. Grilli 2010. On growth drivers of high-tech start-ups: Exploring the role of founders' human capital and venture capital. Journal of Business Venturing 25: 610-626. 
Colombo, M.G. and L. Grilli 2013. The creation of a middle-management level by entrepreneurial ventures: Testing economic theories of organizational design. Journal of Economics \& Management Strategy 22: 390-422.

Cooney, T.M. 2005. Editorial: What is an entrepreneurial team. International Small Business Journal 23: 226-235.

Cooper, A.C. and A.V. Bruno 1977. Success among high-technology firms. Business Horizons 20: 16-22.

Dimov, D. and D. Shepherd 2005. Human capital theory and venture capital firms: exploring "home runs" and "strike outs." Journal of Business Venturing 20: 1-21.

Eckhardt, T. and S. Shane 2003. Opportunities and entrepreneurship. Journal of Management 29: 333-349.

Eisenhardt, K.M. and C.B. Schoonhoven 1990. Organizational growth: Linking founding team, strategy, environment, and growth among U.S. semiconductor ventures, 1978-1988. Administrative Science Quarterly 35: 504-529.

Feeser, H.R. and G.E. Willard 1990. Founding strategy and performance: A comparison of high and low growth high tech firms. Strategic Management Journal 11: 87-98.

Forbes, D.P., P.S. Borchert, M.E. Zellmer-Bruhn and H.J. Sapienza 2006. Entrepreneurial team formation: An exploration of new member addition. Entrepreneurship Theory and Practice 30: 225-248.

Fransman, M. 2004. The telecoms boom and bust 1996-2003 and the role of financial markets. Journal of Evolutionary Economics 14: 369-406.

Ganotakis, P. 2012. Founders' human capital and the performance of UK new technology based firms. Small Business Economics 39: 495-515.

Gartner, W. 1985. A conceptual framework for describing the phenomenon of new venture creation. Academy of Management Review 10: 696-706.

Gimeno, J., T.B. Folta, A.C. Cooper, C.Y. Woo 1997. Survival of the fittest? Entrepreneurial human capital and the persistence of underperforming firms. Administrative Science Quarterly 42: 750-783.

Grilli, L. 2011. When the going gets tough, do the tough get going? The pre-entry work experience of founders and high-tech start-up survival during an industry crisis. International Small Business Journal 29: 626-647.

Hall, J.K., G.A. Daneke and M.J. Lenox 2010. Sustainable development and entrepreneurship: Past contributions and future directions. Journal of Business Venturing 25: 439-448.

Hammar, H. and Å Löfgren 2010. Explaining adoption of end of pipe solutions and clean technologies-Determinants of firms' investments for reducing emissions to air in four sectors in Sweden. Energy Policy 38: 3644-3651.

Ilango, V., R. Subramanian and V. Vasudevan 2011. Cluster analysis research design model, problems, issues, challenges, trends and tools. International Journal on Computer Science and Engineering 3: 3064-3070.

Katila, R., J.D. Rosenberger and K.M. Eisenhardt 2008. Swimming with sharks: Technology ventures, defense mechanisms and corporate relationships. Administrative Science Quarterly 53: 295-332.

Kemp, R. and M. Volpi 2008. The diffusion of clean technologies: A review with suggestions for future diffusion analysis. Journal of Cleaner Production 16: 14-21.

Ketchen, D. and C.L. Shook 1996. The application of cluster analysis in strategic management research: An analysis and critique. Strategic Management Journal 17: 441-458.

Klotz, A.C., K..M. Hmieleski, B.H. Bradley, L.W. Busenitz 2014. New venture teams: A review of the literature and roadmap for future research. Journal of Management 40: 226-255.

Knight, F. 1921. Risk, Uncertainty and Profit. Boston, MA: Houghton Mifflin.

Malerba, F. 2002. Sectoral systems of innovation and production. Research Policy 31: 247-264.

McPherson, M., L. Smith-Lovin and J.M. Cook 2001. Birds of a feather: Homophily in social networks. Annual Review of Sociology 27: 415-444.

Mooi, E. and M. Sarstedt 2011. Understanding Cluster Analysis. In A Concise Guide to Market Research, edited by E. Mooi and M. Sarstedt, 259-283, Heidelberg: Springer.

NuWire Investor 2008. Clean Technology "Boom?”, A Comparison of Internet and Cleantech Venture Capital 
Trends. Internal Company Report.

Packalen, K. 2015. Multiple successful models: how demographic features of founding teams differ between regions and over time. Entrepreneurship \& Regional Development 27: 357-385.

Petkova, A., A.Wadhwa, X. Yao and S. Jain 2014. Reputation and decision making under ambiguity: A study of U.S. venture capital firms' investments in the emerging clean energy sector. Academy of Management Journal 57: 422-448.

Ruef, M., H.E. Aldrich and N. Carter 2003. The structure of founding teams: Homophily, strong ties, and isolation among U.S. entrepreneurs. American Sociological Review 68: 195-222.

Ruiz-Ortega, M.J. and P.M. Garcia-Villaverde 2010. Technology-oriented new ventures and entry timing. International Journal of Technology Management 52: 46-68.

Sawhney, A. and M.E. Kahn 2012. Understanding cross-national trends in high-tech renewable power equipment exports to the United States. Energy Policy 46: 308-318.

Schumpeter, J.A. 1912. The Theory of Economic Development. Cambridge, MA: Harvard University Press.

Schumpeter, J.A. 1942. Capitalism, Socialism and Democracy. London, UK: Allen and Unwin.

Shane, S. 2000. Prior knowledge and the discovery of entrepreneurial opportunities. Organization Science 11: 448469.

Shane, S. 2003. A General Theory of Entrepreneurship: the Individual/Oppurtunity Nexus. Northampton, MA: Edward Elgar Publishing.

Shane, S. and S. Venkataraman 2000. The promise of entrepreneurship as a field of research. Academy of Management Review 25: 217-226.

Vesper, K.H. 1990. New Venture Strategies. Englewood Cliffs, NJ: Prentice Hall.

Vyakarnam, S., R. Jacobs and J. Handelberg 1999. Exploring the formation of entrepreneurial teams: The key to rapid growth business? Journal of Small Business and Enterprise Development 6: 153-165.

Welter, F. 2011. Contextualizing entrepreneurship-conceptual challenges and ways forward. Entrepreneurship Theory and Practice 35: 165-184.

Zacharakis, A.L. and G.D. Meyer 2000. The potential of actuarial decision models: can they improve the venture capital investment decision? Journal of Business Venturing 15: 323-346.

Zahra, S.A. 2007. Contextualizing theory building in entrepreneurship research. Journal of Business Venturing 22: 443-452. 


\section{Tables and figures}

Table 1. Description of variables.

\begin{tabular}{|c|c|}
\hline Variable & Description \\
\hline NumberOfFounders & Number of firm's founders at the time of foundation. \\
\hline TechnicalEducation & Years of scientific or technical education of founder at graduate and post-graduate level. \\
\hline BusinessEducation & Years of economic or managerial education of founder at graduate and post-graduate level. \\
\hline SpecificTechnicalExperience & Years of prior work experience of founder in technical or production functions in the same sector of the start-up. \\
\hline SpecificCommercialExperience & Years of prior work experience of founder in commercial functions in the same sector of the start-up. \\
\hline GenericTechnicalExperience & Years of prior work experience of founder in technical or production functions in other sectors than the start-up. \\
\hline GenericCommercialExperience & Years of prior work experience of founder in commercial functions in other sectors than the start-up. \\
\hline DissimilarityInEducation & Dissimilarity indicator that represents a difference in years of formal education between founder and the corresponding cofounders. \\
\hline DissimilarityInSpecificExperience & $\begin{array}{l}\text { Dissimilarity indicator that represents a difference in years of prior work experience in the same sector of the start-up between founder and the } \\
\text { corresponding cofounders. }\end{array}$ \\
\hline DissimilarityInGenericExperience & $\begin{array}{l}\text { Dissimilarity indicator that represents a difference in years of prior work experience in the other sectors than the one of the start-up between founder and } \\
\text { the corresponding cofounders. }\end{array}$ \\
\hline ComplementarityInEducation & $\begin{array}{l}\text { Complementarity indicator that represents a difference in years of education at graduate and post-graduate level (scientific/technical vs. } \\
\text { economic/managerial degree) between founder and the corresponding cofounders. }\end{array}$ \\
\hline ComplementarityInSpecificExperience & $\begin{array}{l}\text { Complementarity indicator that represents a difference in years of prior work experience in the same sector of the start-up (technical/production vs. } \\
\text { commercial functions) between founder and the corresponding cofounders. }\end{array}$ \\
\hline ComplementarityInGenericExperience & $\begin{array}{l}\text { Complementarity indicator that represents a difference in years of prior work experience in the other sectors than the one of the start-up } \\
\text { (technical/production vs. commercial functions) between founder and the corresponding cofounders. }\end{array}$ \\
\hline
\end{tabular}

CTAS-2016-0036.R2 URL: http://mc.manuscriptcentral.com/ctas 1 E-mail: profjamesfleck@icloud.com - FOR PEER REVIEW ONLY 
Table 2. Correlation matrix.

\begin{tabular}{|c|c|c|c|c|c|c|c|c|c|c|c|c|c|}
\hline Variables & 1 & 2 & 3 & 4 & 5 & 6 & 7 & 8 & 9 & 10 & 11 & 12 & 13 \\
\hline 1 NumberOfFounders & 1.000 & & & & & & & & & & & & \\
\hline 2 TechnicalEducation & $0.145 * *$ & 1.000 & & & & & & & & & & & \\
\hline 3 BusinessEducation & 0.041 & $-0.198 * *$ & 1.000 & & & & & & & & & & \\
\hline 4 SpecificTechnicalExperience & -0.053 & $0.122^{*}$ & -0.066 & 1.000 & & & & & & & & & \\
\hline 5 SpecificCommercialExperience & $-0.137^{*}$ & -0.024 & 0.033 & -0.048 & 1.000 & & & & & & & & \\
\hline 6 GenericTechnicalExperience & 0.021 & 0.098 & -0.069 & $-0.153^{* *}$ & -0.093 & 1.000 & & & & & & & \\
\hline 7 GenericCommercialExperience & -0.048 & $-0.139 *$ & 0.007 & -0.104 & -0.064 & $-0.205^{* *}$ & 1.000 & & & & & & \\
\hline 8 DissimilarityInEducation & 0.079 & 0.002 & 0.042 & $-0.142 * *$ & -0.031 & 0.090 & 0.106 & 1.000 & & & & & \\
\hline 9 DissimilarityInSpecificExperience & $-0.132 *$ & 0.081 & -0.043 & $0.460 * * *$ & 0.117 & -0.110 & -0.097 & -0.012 & 1.000 & & & & \\
\hline 10 DissimilarityInGenericExperience & $-0.155^{* *}$ & -0.089 & 0.076 & -0.030 & 0.002 & $0.172^{* *}$ & 0.106 & $0.311 * * *$ & $0.346^{* * *}$ & 1.000 & & & \\
\hline 11 ComplementarityInEducation & 0.117 & $0.180^{* *}$ & $0.358 * * *$ & $-0.120^{*}$ & -0.049 & 0.083 & -0.056 & $0.537^{* * *}$ & 0.028 & $0.156^{* *}$ & 1.000 & & \\
\hline 12 ComplementarityInSpecificExperience & $-0.138^{*}$ & 0.073 & -0.054 & $0.517^{* *}$ & $0.285^{* * *}$ & $-0.167 * *$ & -0.089 & -0.086 & $0.814 * * *$ & $0.160^{* *}$ & -0.063 & 1.000 & \\
\hline 13 ComplementarityInGenericExperience & -0.075 & $-0.129 *$ & -0.005 & $-0.147^{* *}$ & $-0.136 *$ & $0.389 * * *$ & $0.499 * * *$ & $0.200 * * *$ & -0.083 & $0.404 * * *$ & 0.048 & $-0.181 * *$ & 1.000 \\
\hline
\end{tabular}

Table 3. Cluster analysis results for the three sets of variables: (a) Founders' Human Capital variables,

(b) Team dissimilarity and complementarity variables, (c) Both sets of variables together.

Numbers and percentages (in parenthesis) of founders per cluster.

\begin{tabular}{l|cc|cc|cc}
\hline & \multicolumn{2}{|c|}{ (a) Founders' Human Capital } & \multicolumn{2}{c|}{ (b) Team dissimilarity and } & \multicolumn{2}{c}{ (c) Both sets of variables } \\
variables & \multicolumn{2}{|c|}{ complementarity variables } & \multicolumn{2}{c}{ together } \\
& Cluster 1 & Cluster 2 & Cluster 1 & Cluster 2 & Cluster 1 & Cluster 2 \\
\hline Cleantech founders & $29(53 \%)$ & $25(18 \%)$ & $15(68 \%)$ & $39(23 \%)$ & $31(42 \%)$ & $23(19 \%)$ \\
Internet-based founders & $26(47 \%)$ & $115(82 \%)$ & $7(32 \%)$ & $134(77 \%)$ & $42(58 \%)$ & $99(81 \%)$ \\
\hline
\end{tabular}

CTAS-2016-0036.R2 URL: http://mc.manuscriptcentral.com/ctas 2 E-mail: profjamesfleck@icloud.com - FOR PEER REVIEW ONLY 
Table 4. Mean difference analysis of human capital of the two groups.

\begin{tabular}{|c|c|c|c|c|c|c|c|}
\hline \multirow{3}{*}{$\begin{array}{l}\text { Variable } \\
\text { Number of Founders }\end{array}$} & \multirow{3}{*}{$\begin{array}{l}\text { Sector } \\
\text { Internet-based } \\
\text { Cleantech }\end{array}$} & \multirow{3}{*}{$\begin{array}{c}\text { Obs. } \\
141 \\
54\end{array}$} & \multirow{3}{*}{$\begin{array}{l}\text { Mean } \\
3.078 \\
3.018\end{array}$} & \multirow{3}{*}{$\begin{array}{c}\text { Std.Dev. } \\
1.178 \\
1.107\end{array}$} & \multicolumn{2}{|c|}{ [95\% Conf. Interval] } & \multirow{3}{*}{$\frac{\mathbf{P}(|\mathbf{T}|>|t|)^{1}}{0.749}$} \\
\hline & & & & & 2.882 & 3.274 & \\
\hline & & & & & 2.716 & 3.321 & \\
\hline \multirow[t]{2}{*}{ TechnicalEducation } & Internet-based & 141 & 0.921 & 1.946 & 0.598 & 1.246 & \multirow{2}{*}{$0.000 * * *$} \\
\hline & Cleantech & 54 & 2.852 & 2.759 & 2.099 & 3.604 & \\
\hline \multirow[t]{2}{*}{ BusinessEducation } & Internet-based & 141 & 0.582 & 1.613 & 0.313 & 0.850 & \multirow{2}{*}{0.165} \\
\hline & Cleantech & 54 & 0.241 & 1.273 & -0.107 & 0.588 & \\
\hline \multirow[t]{2}{*}{ SpecificTechnicalExperience } & Internet-based & 141 & 0.631 & 3.041 & 0.125 & 1.138 & \multirow{2}{*}{$0.000^{* * *}$} \\
\hline & Cleantech & 54 & 4.500 & 10.05 & 1.756 & 7.244 & \\
\hline \multirow{2}{*}{ SpecificCommercialExperience } & Internet-based & 141 & 0.440 & 3.041 & -0.067 & 0.946 & \multirow{2}{*}{0.542} \\
\hline & Cleantech & 54 & 0.741 & 3.181 & -0.128 & 1.609 & \\
\hline \multirow[t]{2}{*}{ GenericTechnicalExperience } & Internet-based & 141 & 3.447 & 6.623 & 2.344 & 4.549 & \multirow{2}{*}{$0.024 * *$} \\
\hline & Cleantech & 54 & 6.222 & 9.801 & 3.547 & 8.897 & \\
\hline \multirow[t]{2}{*}{ GenericCommercialExperience } & Internet-based & 141 & 3.064 & 7.723 & 1.778 & 4.350 & \multirow{2}{*}{0.319} \\
\hline & Cleantech & 54 & 1.888 & 6.270 & 0.177 & 3.600 & \\
\hline
\end{tabular}

$$
{ }^{*} \mathrm{p}<0.1,{ }^{* *} \mathrm{p}<0.05,{ }^{* * *} \mathrm{p}<0.01
$$

Table 5. Mean difference analysis of team dissimilarity and complementarity.

\begin{tabular}{|c|c|c|c|c|c|c|c|}
\hline Variable & Sector & Obs. & Mean & Std.Dev. & \multicolumn{2}{|c|}{ [95\% Conf. Interval] } & $\mathbf{P}(|\mathbf{T}|>|t|)^{\uparrow}$ \\
\hline DissimilarityInEducation & $\begin{array}{l}\text { Internet-based } \\
\text { Cleantech }\end{array}$ & $\begin{array}{c}141 \\
54\end{array}$ & $\begin{array}{l}2.220 \\
1.880\end{array}$ & $\begin{array}{l}2.388 \\
2.812\end{array}$ & $\begin{array}{l}1.823 \\
1.112\end{array}$ & $\begin{array}{l}2.618 \\
2.647\end{array}$ & 0.397 \\
\hline \multirow{2}{*}{ DissimilarityInSpecificExperience } & Internet-based & 141 & 1.224 & 3.662 & 0.614 & 1.834 & \multirow{2}{*}{$0.000 * * *$} \\
\hline & Cleantech & 54 & 4.389 & 7.827 & 2.253 & 6.525 & \\
\hline \multirow{2}{*}{ DissimilarityInGenericExperience } & Internet-based & 141 & 6.852 & 7.398 & 5.620 & 8.084 & \multirow{2}{*}{0.109} \\
\hline & Cleantech & 54 & 9.015 & 10.58 & 6.127 & 11.90 & \\
\hline \multirow{2}{*}{ ComplementarityInEducation } & Internet-based & 141 & 1.888 & 2.303 & 1.505 & 2.271 & \multirow{2}{*}{0.915} \\
\hline & Cleantech & 54 & 1.848 & 2.286 & 1.224 & 2.472 & \\
\hline \multirow{2}{*}{ ComplementarityInSpecificExperience } & Internet-based & 141 & 0.944 & 3.308 & 0.393 & 1.494 & \multirow{2}{*}{$0.000 * * *$} \\
\hline & Cleantech & 54 & 5.070 & 8.872 & 2.648 & 7.492 & \\
\hline \multirow[t]{2}{*}{ ComplementarityInGenericExperience } & Internet-based & 141 & 7.212 & 8.689 & 5.765 & 8.659 & \multirow{2}{*}{0.461} \\
\hline & Cleantech & 54 & 8.332 & 11.27 & 5.254 & 11.41 & \\
\hline
\end{tabular}

CTAS-2016-0036.R2 URL: http://mc.manuscriptcentral.com/ctas 3 E-mail: profjamesfleck@icloud.com - FOR PEER REVIEW ONLY 
Figure 1. Results of the cluster analysis using three different sets of variables: (a) Founders' human capital variables, (b) Team dissimilarity and complementarity variables, (c) Both sets of variables together.
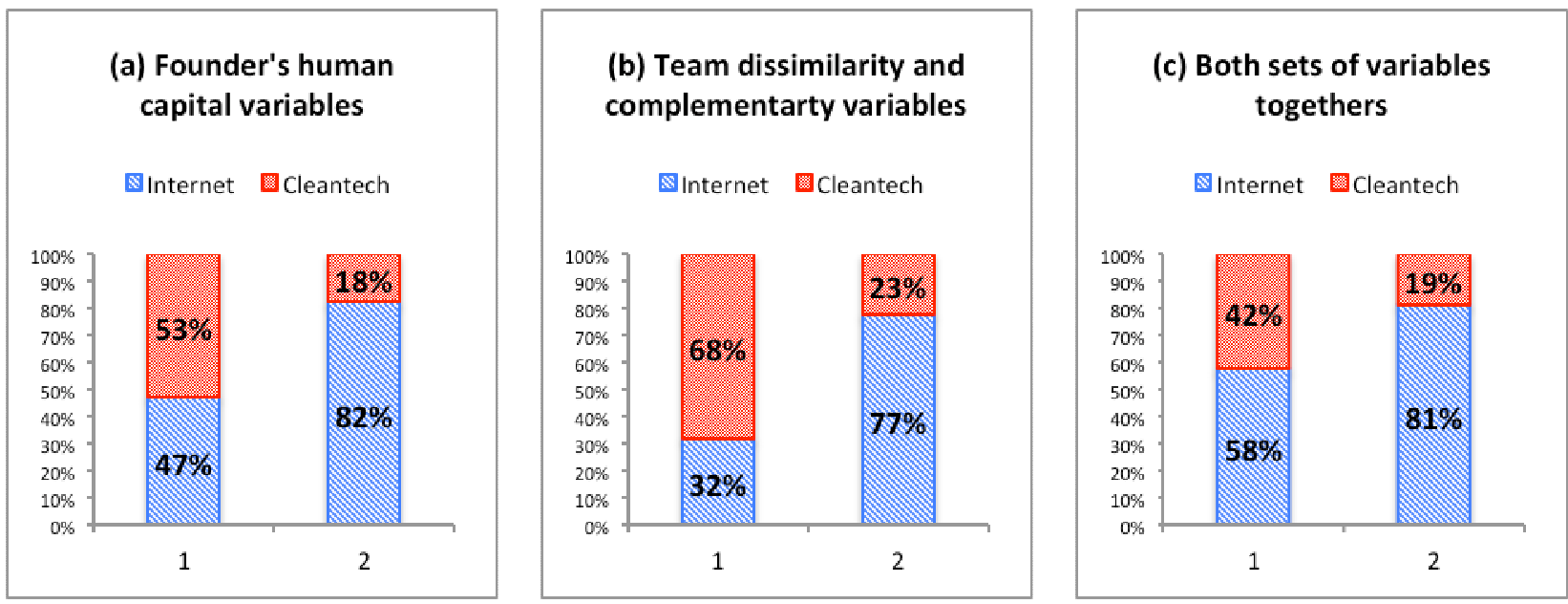

CTAS-2016-0036.R2 URL: http://mc.manuscriptcentral.com/ctas 4 E-mail: profjamesfleck@icloud.com - FOR PEER REVIEW ONLY 